\title{
Antioxidant Activity of the Extracts from Pycnoporus sanguineus Mycelium
}

\author{
Josiane Borderes ${ }^{1}$, Alessandra Costa $^{2}$, Alessandro Guedes ${ }^{3}$ and Lorena Benathar Ballod \\ Tavares $^{3 *}$ \\ ${ }^{I}$ Universidade Regional de Blumenau; Rua São Paulo, 3250; 89030-000; Blumenau - SC - Brasil. ${ }^{2}$ Departamento \\ de Engenharia Química; Universidade Regional de Blumenau; Rua São Paulo, 3250; 89030-000; Blumenau - SC - \\ Brasil. ${ }^{3}$ Departamento de Ciências Farmacêuticas; Universidade Regional de Blumenau; Rua São Paulo, 3052; \\ 89030-000; Blumenau - SC - Brasil
}

\begin{abstract}
The aim of this work was to study the production of compounds with antioxidant activity by Pycnoporus sanguineus when cultivated in submerged fermentation using a potato dextrose broth plus peptone medium. The study evaluated the biomass production, glucose consumption, variation of medium $\mathrm{pH}$ and antioxidant activity. The antioxidant potential was tested through the DPPH method and $\beta$-carotene / linoleic acid system with extracts obtained from the mycelium at different times of cultivation (5, 10, 15, 20, 25 and 30 days). Maximum kinetic values of specific growth rate $\left(0.289\right.$ day $\left.^{-1}\right)$, biomass productivity $\left(0.698 \mathrm{~g} \cdot \mathrm{L}^{-1}\right.$. day $\left.{ }^{-1}\right)$ and the yield of glucose conversion into biomass $(26.24$ $\left.g . g^{-1}\right)$ were obtained during the exponential growth phase. The highest antioxidant activity was registered during the stationary phase, with a similar potential as the synthetic antioxidant BHT, in the extracts obtained at 30 days of cultivation.
\end{abstract}

Key words: Basidiomycetes; Submerged culture; Kinetics; Antioxidant compounds

\section{INTRODUCTION}

Pycnoporus sanguineus acts as a synthesizer of some pigments. One of them, cinnabarin, has antibacterial properties (Smânia et al., 1995) with good therapeutic potential and pharmacological application. Ramos et al. (2006) found that cinnabarin was not the main compound synthesized by $P$. sanguineus. Therefore, it is necessary to identify other substances produced by this fungus, in order to verify its potential as an important source of commercial bioactive products.
Plants have become an important source of biologically active products since the substances which they contain, enzymes, proteins, flavonoids, carotenoids, among others, act in different ways (Argolo et al., 2004). Nowadays, as the control of biological processes has become possible, both plants and Basidiomycete fungi are being actively investigated as relevant biological materials for the pharmaceutical industry.

Recent studies have highlighted the bioactive compounds obtained from fungi (Di Piero et al., 2010), particularly antioxidants (Cui et al., 2005), which significantly delay or prevent the oxidation

*Author for correspondence: lorena@furb.br 
of this substrate when present at low concentrations compared with other oxidizing substrates (Ai-li and Chang-hai, 2006). In order to reduce the free radical production and consequent cell damage, the use of natural antioxidants has been widely studied (Vieira et al., 2008). Several species of fungi contain a large diversity of molecules which scavenge the free radicals or reactive oxygen species (Mau et al., 2002).

The interest in finding natural antioxidants for use in the food products and the pharmaceutical markets has grown notably since the early 1980s. The investigations aim at replacing the commonly used synthetic antioxidants such as butylhydroxytoluene (BHT) and butylhydroxyanisole (BHA), which have been prohibited due to their carcinogenic potential as well as other health problems they may cause, including a gain in liver weight and the considerable proliferation of the endoplasmatic reticule (Melo and Guerra, 2002; Pastene et al., 2001).

Many studies have highlighted the benefits of the consumption of antioxidant substances in daily diet. This can result in an effective action to protect the organism against the oxidative processes. It was discovered that several diseases, including cancer, arteriosclerosis, diabetes, arthritis, malaria, AIDS, and heart disease, may be linked to the damage caused by different forms of extremely reactive oxygen, called reactive oxygen species (ROS). These substances are also related to the human ageing process (Brenna and Pagliarini, 2001).

Studies on the above-mentioned active components have increased due to the interest in the food, drug, cosmetics and nutraceutical industries. Therefore, this study aimed at evaluating the production of active compounds with antioxidant properties by $P$. sanguineus cultivated in a potato dextrose broth plus peptone medium.

\section{MATERIALS AND METHODS}

\section{Microorganism and inoculum preparation}

Pycnoporus sanguineus (strain MIP 9500-1) was obtained from the Antibiotics Laboratory at the Federal University of Santa Catarina in southern Brazil. Fungal culture was maintained on potato dextrose agar (PDA, HiMedia, India), incubated at
$25{ }^{\circ} \mathrm{C}$ for seven days, and stored at $4{ }^{\circ} \mathrm{C}$. The inoculum was prepared in a medium containing $15.0 \mathrm{~g}$ of eucalyptus sawdust, $2.0 \mathrm{~g}$ of cassava starch, $2.0 \mathrm{~g}$ of soy bran and distilled water (100 $\mathrm{mL})$. All the flasks were inoculated with the slices of fresh mycelium grown on PDA and incubated at $25^{\circ} \mathrm{C}$ in the absence of light for up to 30 days.

\section{Fermentation conditions}

The submerged fermentation was carried out in $500 \mathrm{~mL}$ flasks containing $150 \mathrm{~mL}$ of culture medium prepared with $(\mathrm{g} / \mathrm{L}) 2.4$ potato dextrose broth (PDB, HiMedia, India) and 0.1 of bactopeptone (BD, France), inoculated with approximately $2.0 \mathrm{~g}$ of inoculum. It was incubated at $25{ }^{\circ} \mathrm{C}$ for 30 days, in the absence of light and under aerobic conditions. The initial $\mathrm{pH}$ was not adjusted. The biomass, $\mathrm{pH}$, glucose consumption and antioxidant activity were determined after every five days of cultivation.

\section{Determination of dry cell mass and specific growth rate}

In order to determine the fungal biomass, the mycelium was vacuum filtered and dried to constant weight $\left(60{ }^{\circ} \mathrm{C}\right)$. It was placed in a desiccator and the mass was determined. The biomass concentration was calculated as the ratio between the dry cell mass and the volume of the medium. In order to determine the specific growth rate $(\mu)$, the natural $\log$ of the biomass $(\ln X)$ was plotted against the fermentation time $(t)$. For any given moment the slope of the line gives the specific growth rate. Maximum kinetic parameters were evaluated during the exponential phase of the cultivation as well as the maximum specific growth rate $\left(\mu_{\mathrm{X} \max }\right)$, maximum biomass productivity $\left(\mathrm{P}_{\mathrm{Xmax}}\right)$ and maximum yield of glucose conversion into biomass $\left(\mathrm{Y}_{\mathrm{X} / \mathrm{Smax}}\right)$.

\section{Determination of residual glucose and $\mathrm{pH}$}

The residual glucose concentration in the medium was determined by the enzymatic method of glucose oxidase (GOD) using a test kit for the enzymatic liquid glucose determination (Doles, Brazil). The method was based on test kit instructions. The extracts $(20 \mu \mathrm{L})$ were mixed with $2.0 \mathrm{~mL}$ of the colored reagent and the absorbance was read at $500 \mathrm{~nm}$ (Spectrophotometer UV-1650, Shimadzu) after 10 min. The glucose concentration $(C)$ was calculated according to the equation: 
$C=\frac{C s}{A s} \times$ Asample,

where $A_{\text {sample }}$ is the absorbance of the sample, As is the absorbance of the standard and $C s$ is the standard concentration.

The $\mathrm{pH}$ was determined by the direct measurement in the filtered medium using a $\mathrm{pH}$ meter.

\section{Extraction of the antioxidant compounds}

In order to extract the antioxidant compounds, 50 $\mathrm{mL}$ of ethanol (Vetec, Brazil) were added to $2.0 \mathrm{~g}$ of dry and powered mycelium. This was left for three days under agitation of $80 \mathrm{rpm}$ and the ethanol was changed every day. Then it was left for a further three days without agitation and without changing the ethanol. After this period, the ethanolic fractions were pooled and concentrated using a rotary evaporator (Quimis, Brazil) at $50^{\circ} \mathrm{C}$.

\section{Evaluation of antioxidant activity of the extracts}

The scavenging effects of the samples on DPPH were monitored according to the method developed by Tepe, (2008). Various concentrations $(0.25,0.5,1.0,2.0,3.0,4.0,5.0$ mg. $\left.\mathrm{mL}^{-1}\right)$ of methanolic extracts from $P$. sanguineus $(0.5 \mathrm{~mL})$ were mixed with $1.5 \mathrm{~mL}$ of a $0.004 \%$ methanolic solution of DPPH (Aldrich, Germany). The mixture was vortexed and left to stand for $30 \mathrm{~min}$. The reduction of DPPH radical was determined by measuring the absorption at $517 \mathrm{~nm}$ and the \% of inhibition (I \%) was calculated according to the equation:

$$
I \%=\frac{\text { Ablank }- \text { Asample }}{\text { Ablank }} \times 100
$$

where $A_{\text {blank }}$ is the absorbance of the control reaction (containing all reagents except the extract) and $A_{\text {sample }}$ is the absorbance of the test compound. Extract concentration causing $50 \%$ inhibition $\left(\mathrm{IC}_{50}\right)$ was calculated from the graph, plotting the \% inhibition against extract concentration. All the tests were carried out in triplicate. BHT (Aldrich, Germany) was used as a positive control.

\section{Antioxidant activity by $\beta$-carotene / linoleic acid assay}

The antioxidant activity was measured using the method of Mokbel and Hashinaga (Mokbel and
Hashinaga, 2006), which was slightly modified. A solution of $\beta$-carotene (Sigma, Germany) in chloroform (Vetec, Brazil) $\left(3 \mathrm{mg} \cdot \mathrm{mL}^{-1}\right)$ was mixed with $45 \mathrm{mg}$ of linoleic acid (Vetec, Brazil) and 215 mg of Tween-80 (Vetec, Brazil). The chloroform was removed at $45{ }^{\circ} \mathrm{C}$ under vacuum using a rotary evaporator and $6 \mathrm{~mL}$ of distilled water was added under vigorous shaking. The emulsion was then made up to $100 \mathrm{~mL}$ with $0.1 \mathrm{M}$ hydrogen peroxide (Vetec, Brazil). Aliquots $(4.0 \mathrm{~mL})$ of this emulsion were transferred into different glass tubes containing $0.2 \mathrm{~mL}$ of test samples (methanolic extracts from $P$. sanguineus at a concentration of $1 \mathrm{mg} \cdot \mathrm{mL}^{-1}$ ). A blank experiment was prepared as above, but without $\beta$-carotene, and BHT was used as a positive control. A negative control containing $0.2 \mathrm{~mL}$ of methanol (Vetec, Brazil) and $4.0 \mathrm{~mL}$ of the above emulsion was also prepared. The tubes were placed in a water bath at $50{ }^{\circ} \mathrm{C}$. All the determinations were carried out in triplicate. The absorbance of each sample, at $470 \mathrm{~nm}$, was taken at zero time and every $20 \mathrm{~min}$ for $100 \mathrm{~min}$. The antioxidant activity of the extracts was expressed as \% of oxidative inhibition of $\beta$-carotene/linoleic acid system (I \%) according to the equation:

$$
I \%=\left(\frac{1-A_{0}-A_{t}}{A_{0}^{\prime}-A_{t}^{\prime}}\right) \times 100
$$

where $A_{0}$ and $A_{0}$ ' are the absorbance values measured at zero time for the test sample and control, respectively; while $A_{t}$ and $A_{t}{ }^{\prime}$ are the absorbance values measured for test sample and control, respectively, after $100 \mathrm{~min}$.

The antioxidant effectiveness in this assay was estimated by the tangent (tg) method, using two different parts of the kinetic curves (Yanishilieva and Marinova, 1995). Based on the data obtained after every $20 \mathrm{~min}$, decay of the sample absorbance (Abs) was plotted against reaction time (t). Using the first part of the curve (20 and 40 min), the antioxidant capacity to block the chain reaction (F1 - stabilization factor) through peroxide-radical interaction was measured. Using the second part of the curve (80 and $100 \mathrm{~min}$ ), the possible participation of antioxidant (F2 protection factor) in other reactions during the oxidative process was measured. These factors expressed a relation between the tangents of kinetic curves of the test sample and control. The values lower than one showed that the samples did 
act as antioxidants. F1 and F2 values were calculated according to the equations:

$$
F 1=\frac{\operatorname{tg}_{\text {extract }_{(20-40)}}}{{\text { tg } \operatorname{control}_{(20-40)}}_{\left(20 \operatorname{control}_{(80-100)}\right.}}
$$

The results of antioxidant activity were statistically analyzed by one-way analysis of variance (ANOVA). Statistical differences at $p$ values under 0.05 were considered significant and subsequently compared using the Tukey's test.

\section{RESULTS AND DISCUSSION}

\section{Kinetics of $P$. sanguineus growth and antioxidant activity}

The analysis of $P$. sanguineus growth in Fig. 1 showed the occurrence of an exponential phase, which started on $5^{\text {th }}$ day of cultivation and ended on $10^{\text {th }}$ day. The maximum kinetic parameters were calculated within this period.

The maximum specific growth rate $\left(\mu_{\mathrm{X} \max }\right)$ was 0.289 day $^{-1}$; the maximum biomass productivity
$\left(\mathrm{P}_{\mathrm{Xmax}}\right)$ was 0.698 g.L $\mathrm{L}^{-1}$ day $^{-1}$ and maximum yield of glucose conversion indo biomass $\left(\mathrm{Y}_{\mathrm{X} / \mathrm{Smax}}\right)$ was 26.24 g. $\mathrm{g}^{-1}$. During the cultivation, the mycelial growth was noted, followed by a decrease in the substrate concentration with an average consumption of 0.048 g. $\mathrm{L}^{-1} \cdot \mathrm{day}^{-1}$. The glucose present in the medium was totally consumed before 30 days, which indicated a correlation between glucose consumption and biomass production.

The stationary phase was observed after day 10 of cultivation, although the cell concentration on day 15 was higher than those obtained on days 20,25 and 30 . This could be explained by the difference in the cell concentrations in different flasks. During this phase, the medium $\mathrm{pH}$, which was initially 5.0, remained at around 3.8.

According to Demain, (2000), the growth curves of microorganism have a direct relation with the metabolic processes developed by fungi. The maximum production of antioxidants by $P$. sanguineus occurred during the stationary phase (Fig. 1).

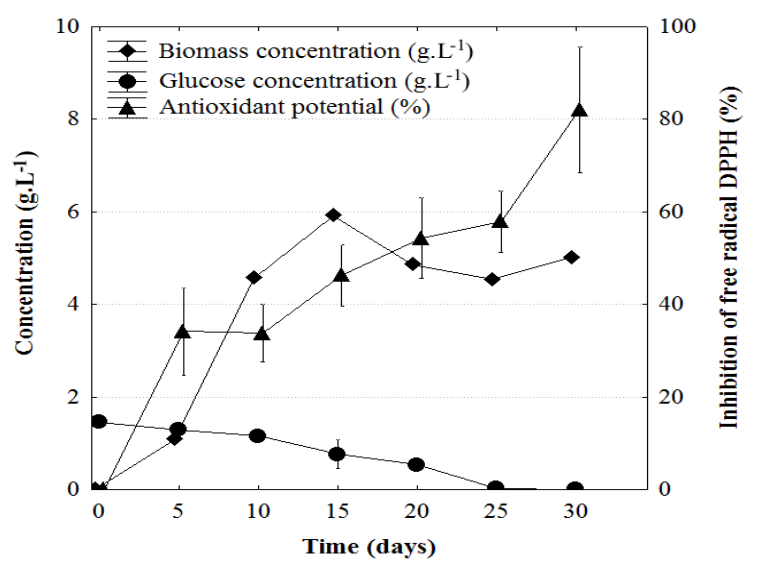

Figure 1 - Kinetics of biomass production, glucose consumption and antioxidant potential of the fungal extract against the free radical DPPH at a concentration of $3.0 \mathrm{mg} \cdot \mathrm{mL}^{-1}$, using $P$. sanguineus submerged fermentation.

The absence of a value for the initial cellular concentration was due to the difficulty in separating the mycelium from the sawdust, which would enable its quantification. Thus, during each sample collection to evaluate the cell concentration, the mass of the inoculum was neglected.

Ramos et al. (2006) investigated the growth kinetics of $P$. sanguineus, and obtained similar biomass values to those found in this study.
However, these values were observed after a longer time of cultivation. The same values found by these authors on day 20 of cultivation, were observed in the present study on day 10. This difference in the growth rates could be related to the inoculum used. This inoculum was cultivated in a lignocellulosic material (sawdust), which simulated fungal natural growth conditions. However, in the above-mentioned study, the inoculum came from a BDA medium. 


\section{Antioxidant activity of the extracts}

DPPH radical scavenging assay

All the extracts showed antioxidative activity based on DPPH free radical scavenging (Table 1). However, the extract obtained on the day 30 of cultivation was the one which presented the highest antioxidant activity. The extracts obtained after $5^{\text {th }}$ and $10^{\text {th }}$ days could scavenge only $50 \%$ of the free radicals in the solution at high concentrations, presenting the highest $\mathrm{IC}_{50}$ values. The best results for DPPH free radical scavenging, found at 30 days of cultivation, could be related to the stationary growth phase of $P$. sanguineus.

Table 1 - Radical scavenging capacities of $P$. sanguineus extracts shown as inhibition concentration $\left(\mathrm{IC}_{50}\right)$ and determined by the reduction of DPPH free radical. The standard deviation is represented by the linear correlation coefficient $\left(\mathrm{R}^{2}\right)$ curve of inhibition plotted against extract concentration.

\begin{tabular}{ccc}
\hline Samples & $\mathbf{I C}_{\mathbf{5 0}}\left(\mathbf{m g . \mathbf { m L } ^ { \mathbf { - 1 } }}\right)^{*}$ & Correlation coefficient-R $^{\mathbf{2}}$ \\
\hline 5 days & 5.67 & 0.9634 \\
10 days & 4.32 & 0.9986 \\
15 days & 3.47 & 0.9920 \\
20 days & 2.91 & 0.9885 \\
25 days & 2.84 & 0.9727 \\
30 days & 1.62 & 0.9598 \\
\hline
\end{tabular}

* $\mathrm{IC}_{50}$ represents the extract concentration needed to reduce $50 \%$ of the initial DPPH concentration

Barros et al. (2007) investigated the antioxidant activity of the mycelium extracts of Leucopaxillus giganteus, Sarcodon imbricatus and Agaricus arvensis using the free radical DPPH. The values obtained for $\mathrm{IC}_{50}$ were $1.44 \mathrm{mg} . \mathrm{mL}^{-1}, 1.67 \mathrm{mg} . \mathrm{mL}^{-}$ ${ }^{1}$ and $3.50 \mathrm{mg} \cdot \mathrm{mL}^{-1}$, respectively. Similar values were obtained for $P$. sanguineus.

The inhibition of DPPH by the different concentrations of $P$. sanguineus extracts collected on different days of cultivation and also by BHT is shown in Figure 2. Good linearity in the curves obtained from the extracts, with correlation coefficients above 0.95 , was noted. These results showed that an increase in the sample concentration led to an increase in the antioxidant activity. The same finding was described by Gursoy et al. (2010), who analyzed the methanolic extracts of Ramaria flava, Rhizopogon roseolus and Russula delica mushroom for antioxidant activity. In DPPH system, these authors evaluated the extracts with concentrations from 0 to $12 \mathrm{mg} \cdot \mathrm{mL}^{-1}$. R. flava showed the maximum inhibition (almost $95 \%$ ) with between 6.0 and 8.0 mg.mL ${ }^{-1}$. The other fungi presented less inhibition even with the highest concentration tested.

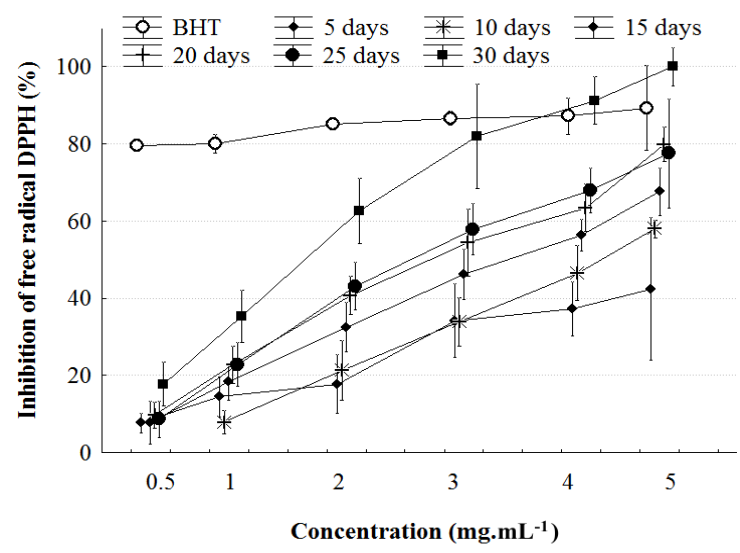

Figure 2 - Radical scavenging activities of $P$. sanguineus extracts and synthetic antioxidant (BHT) shown as inhibition \% and determined by the reduction in the free radical DPPH. 
Figure 3 shows the antioxidant activity of the extracts, which were evaluated at a concentration of $3 \mathrm{mg} \cdot \mathrm{mL}^{-1}$. A different behavior was observed, with higher production of the antioxidant by $P$. sanguineus occurring after the day 20 of cultivation. At this time the concentration of 3.0 mg.mL $\mathrm{mL}^{-1}$ showed over $50 \%$ inhibition of the DPPH radical. When comparing the samples with each other and with the synthetic antioxidant (BHT) at a concentration of $3.0 \mathrm{mg} \cdot \mathrm{mL}^{-1}$, results found for the extract of $P$. sanguineus showed remarkable antioxidant activity. The sample collected on the day 30 showed radical scavenging activity (DPPH) similar to that presented by the synthetic antioxidant BHT $(\mathrm{p}<0.05)$. Furthermore, the extracts collected on the day 15 had mild antioxidant activity and those collected on the days 5 and 10 showed a low inhibition of the DPPH radical.

Means with different letters (a-d) differ significantly according to the Tukey's test ( $\mathrm{p}<$ $0.05)$.

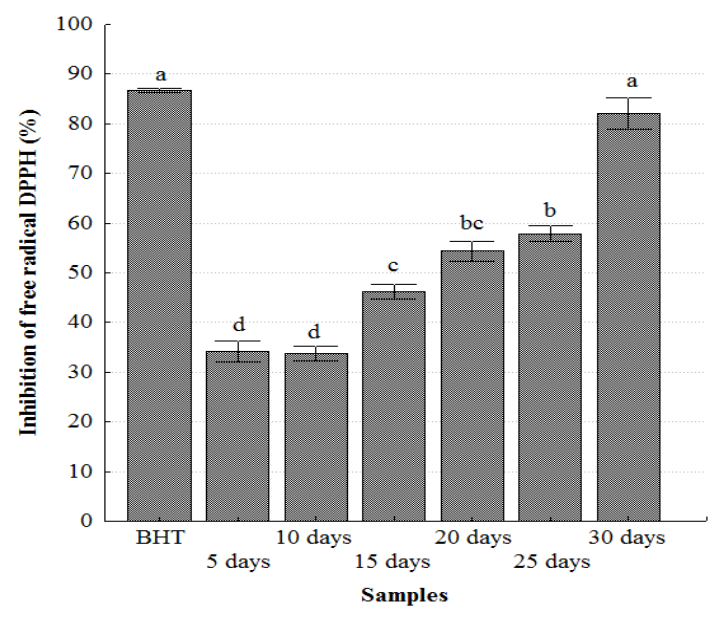

Figure 3 - Kinetic behavior of free radical scavenging activities of $P$. sanguineus extracts and synthetic antioxidant BHT at a concentration of $3.0 \mathrm{mg} \cdot \mathrm{mL}^{-1}$, measured by DPPH assay.

\section{Antioxidant activity by $\beta$-carotene / linoleic acid assay}

Table 2 shows the oxidative inhibition after 100 minutes of reaction and at a concentration of 1 mg. $\mathrm{mL}^{-1}$ in $\beta$-carotene / linoleic acid system. These results suggested that at this concentration the extract of $P$. sanguineus presented inferior antioxidant activity when compared to that presented by the synthetic antioxidant BHT. In addition, the best results were obtained with the samples collected on the days 30 and 25 day of the cultivation.
All the samples collected from $P$. sanguineus at the concentration of $1.0 \mathrm{mg} \cdot \mathrm{mL}^{-1}$ showed over $50 \%$ inhibition of the oxidation system. These results were better than those obtained in the antioxidant test using DPPH method.

In a study by Barros et al., (2007), a higher antioxidant activity of $L$. giganteus, $S$. imbricatus and $A$. arvensis in a $\beta$-caroteno / linoleic acid system was obtained with an increase in the concentration and the activities which were obtained at a concentration of $5.0 \mathrm{mg} \cdot \mathrm{mL}^{-1}$ were $61.4,54.3$ and $46.7 \%$, respectively.

Table 2 - \% of oxidative inhibition $\%$ of $\beta$-carotene/linoleic acid system by $P$. sanguineus extracts and synthetic antioxidant (BHT) at a concentration of $1.0 \mathrm{mg} \cdot \mathrm{mL}^{-1}$, measured in $\beta$-carotene / linoleic acid assay.

\begin{tabular}{cc}
\hline Samples & Inhibition $(\%)^{*}$ \\
\hline BHT & $89 \pm 0.016^{\mathrm{a}}$ \\
30 days & $79 \pm 0.047^{\mathrm{b}}$ \\
25 days & $65 \pm 0.008^{\mathrm{bc}}$ \\
20 days & $58 \pm 0.026^{\mathrm{c}}$ \\
15 days & $63 \pm 0.049^{\mathrm{c}}$ \\
\hline
\end{tabular}

*Each value is presented as mean \pm SD $(n=3)$. Means by different letters $(a-c)$ differ significantly at Tukey's test $(\mathrm{p}<0.05)$. 
In order to complete the antioxidant activity evaluation of the extracts, their efficiency was verified by the analysis of kinetics curves plotted for discoloration of $\beta$-carotene against the incubation time, through the calculation of the factors F1 (stabilization) and F2 (protection). The F1 values for $P$. sanguineus extracts (Table 3), indicated a capacity to block the initial formation of free radicals. However, the lower efficiency of the extracts was observed when compared to that of BHT at all the tested concentrations. In the propagation phase, the $\mathrm{F} 2$ values also showed antioxidant efficiency of the extracts.

Table 3 - Kinetic parameters representing the oxidative inhibition of $\beta$-carotene/linoleic acid system by $P$. sanguineus extracts and synthetic antioxidant (BHT) at a concentration of $1.0 \mathrm{mg} . \mathrm{mL}^{-1}$.

\begin{tabular}{ccc}
\hline \multirow{2}{*}{ Samples } & \multicolumn{2}{c}{ Kinetic factors } \\
\cline { 2 - 3 } & F1* & F2** \\
\hline BHT & $0.144 \pm 0.008$ & $0.148 \pm 0.021$ \\
30 days & $0.295 \pm 0.023$ & $0.240 \pm 0.056$ \\
25 days & $0.371 \pm 0.013$ & $0.545 \pm 0.011$ \\
15 days & $0.364 \pm 0.026$ & $0.855 \pm 0.015$ \\
\hline
\end{tabular}

* When the stabilization factor (F1) is lower than 1.0, indicates that the antioxidants in the extract are capable to block the chain reaction through peroxide-radical interaction.

**When the protection factor $(\mathrm{F} 2)$ is lower than 1.0, indicates that the antioxidants in the extract may participate in other reactions during oxidative process.

\section{CONCLUSIONS}

P. sanguineus presented a satisfactory antioxidant potential when compared to other fungi. The best results indicated that this was performed by active compounds of secondary metabolism of this fungus, and their production was not related to the cell multiplication. $P$. sanguineus showed potential to act as a natural source of antioxidant compounds. Hence, it could be of great importance to develop further studies addressing the issues such as the purification and identification of these compounds.

\section{ACKNOWLEDGEMENTS}

The authors acknowledge Prof. Dr. Artur Smânia Júnior for supplying of strains of $P$. sanguineus; and are also grateful for the financial support from Programa de Incentivo a Pesquisa (PIPe/Research Incentive Program) and Coordenação de Aperfeiçoamento de Pessoal de Nivel Superior (CAPES/ Brazilian Education Council).

\section{REFERENCES}

Ai-li, J.; Chang-hai, W. (2006), Antioxidant properties of natural components from Salvia plebeia on oxidative stability of ascidian oil. Process Biochem., 41, 11111116.

Argolo, A. C. C.; Sant'Ana, A. E. G.; Pletsch, M.; Coelho, L. C. B. B. (2004). Antioxidant activity of leaf extracts from Bauhinia monandra. Bioresour. Technol., 95, 229233.

Barros, L.; Ferreira, M. J.; Queirós, B.; Ferreira, I.C.F.R.; Baptista, P. (2007), Total phenols, ascorbic, $\beta$-carotene and lycopene in Portuguese wild edible mushrooms and their antioxidant activities. Food Chem., 103, 413-419.

Brenna, O.V.; Pagliarini, E. (2001), Multivariate analyses of antioxidant power and polyphenolic composition in red wines. J. Agric. Food Chem., 49, 4841-4844.

Cui, Y.; Kim, D. S.; Park, K. C. (2005), Antioxidant effect of Inonotus obliquus. J. Ethnopharmacol, 96, 7985.

Demain, A. L. (2000), Microbial biotechnology. Trends Biotechnol., 18, 26-31.

Di Piero, R.M; Novaes, Q.S.; Pascholati, S.F. (2010), Effect of Agaricus brasiliensis and Lentinula edodes mushrooms on the infection of passionflower with Cowpea aphid-borne mosaic virus. Braz. Arch. Biol. Technol., 53, 2, 269-278.

Gorsoy, N.; Sarikurkcu, C.; Tepe, B.; Solak, M. H. (2010), Evaluation of antioxidant activities of 3 edible mushrooms: Ramaria flava (Schaef.: Fr.) Quél., Rhizopogon roseolus (Corda) T.M. Fries., and Russula delica Fr. Food Sci. Biotechnol., 19, 3, 691-696.

Li, J.; Din, S.; Ding, X. (2005), Comparison of antioxidant capacities of extracts from five cultivars of Chinese jujube. Process Biochem., 40, 3607-3613.

Mau, J. L.; Lin, H. C.; Chen, S. T. (2002), Antioxidant properties of several medicinal mushrooms. J. Agric. Food Chem., 50, 6072-6077. 
Melo, E. A.; Guerra, N. B. (2002), Ação antioxidante de compostos fenólicos naturalmente presentes em alimentos. Bol. SBCTA., 36, 1-11.

Mokbel, M. S.; Hashinaga, F. (2006), Evaluation of the antioxidant activity of extracts from buntan (Citrus grandis Osbeck) fruit tissues. Food Chem., 94, 529534.

Pastene, E. R.; Wilkomirsky, T.; Bocaz, G.; Havel, J. Peric, I.; Veja, M.; González, M.; Alderete, J. (2001) Uso de espectroscopia de RMN y MALDI-TOF-MS en la elucidacion estructural de flavonoides antioxidantes provenientes de la planta medicinal chilena Cheilanthes glauca (Cav.) Mett. Bol. Soc. Chil. Quím., 46, 449-457.

Ramos, R. C.; Liebl, M.; Vieira, G. R. T.; Guedes, A. L.; Tavares, L. B. B.; Furigo, Jr. (2006), A. Cinética de crescimento de Pycnoporus sanguineus em sistema submerso para produção de compostos antibacterianos. In: Congresso brasileiro de termodinâmica aplicada, 2, Santos.. Anais do COBEQ.

Smânia, Jr. A.; Delle, M. F.; Smânia, E. F. A.; Gil, M. L.; Benchetrit, L. C.; Cruz, F. S. (1995), Antibacterial activity of a substance produced by the fungus Pycnoporus sanguineus (Fr) Murr. J. Ethnopharmacol, 45, 177-181.
Tepe, B. (2008), Antioxidant potentials and rosmarinic acid levels of the methanolic extracts of Salvia virgata (Jacq), Salvia staminea (Montbret and Aucher ex Bentham) and Salvia verbenaca (L.) from Turkey. Bioresour. Technol., 99, 1584-1588.

Vattem, D. A.; Shetty, K. (2003), Ellagic acid production and phenolic antioxidant activity in cranberry pomace (Vaccinium macrocarpon) mediated by Lentinus edodes using a solid-state system. Process Biochem., 39, 367379.

Vieira, G. R. T.; Liebl, M.; Tavares, L. B. B.; Paulert, R.; Smânia, Jr. A.; (2008), Submerged culture conditions for the production of mycelial biomass and antimicrobial metabolites by Polyporus tricholoma Mont. Braz. J. Microbiol., 39, 561-568.

Yanishilieva, N. V. I.; Marinova, E. M. (1995), Effects of antioxidants on the stability of triacylglycerols and methyl esters of fatty acids of sunflower oil. Food Chem., 54, 377-382.
Received: June 21, 2010; Revised: January 20, 2010; Accepted: August 09, 2011. 